\title{
Reproductive management practices and performance of Canadian dairy herds using automated activity-monitoring systems
}

\author{
R. C. Neves and S. J. LeBlanc ${ }^{1}$ \\ Department of Population Medicine, University of Guelph, Ontario, Canada N1G 2W1
}

\section{ABSTRACT}

The objectives of this study were to describe the characteristics and motivations of producers who had implemented automated activity-monitoring (AAM) systems and to compare herd reproductive performance before and after the implementation of an AAM system and between herds with AAM and herds managing reproduction based on timed artificial insemination (TAI) or based on other programs. Freestall dairy herds located in Ontario and the western provinces of Canada and enrolled in Dairy Herd Improvement were surveyed through a mail questionnaire between April and July 2010. The data describe the characteristics and reproductive management practices of herds using AAM systems. A total of 505 questionnaires (29\%) were returned. On average, 21-d pregnancy risk, conception risk, and 21-d insemination risk did not differ between herds managing reproduction based on an AAM system $(18,39$, and $50 \%$, respectively) or a TAIbased program $(17,38$, and $49 \%$, respectively). Herds that implemented an AAM system had a significant increase in annual pregnancy risk, from 15 to $17 \%$, and insemination risk increased from 42 to $50 \%$, whereas conception risk was unchanged (37 and 35\%) following adoption of the system. The majority of respondents with AAM systems first used the system to manage reproduction in lactating cows. Most herds with AAM were performing artificial insemination twice per day, most commonly with an interval from the estrus alarm to artificial insemination of 7 to $12 \mathrm{~h}$. The most commonly reported reason to adopt an AAM system was a desire to improve reproductive performance. These results support the findings from randomized trials that AAM-based programs can yield comparable reproductive performance to TAI-based programs.

Key words: survey, reproduction, activity-monitoring system, estrus detection

Received April 9, 2014.

Accepted December 30, 2014

${ }^{1}$ Corresponding author: sleblanc@uoguelph.ca

\section{INTRODUCTION}

Intensive and accurate estrus detection in dairy herds is a long-standing and ongoing challenge. If superior rates of detection of estrus can be achieved, reproductive programs based on estrus detection can be as profitable as timed artificial insemination (TAI) programs with excellent compliance to the protocol (Galvão et al., 2013). Estrus detection efficiency in many North American dairy herds is less than optimal (Senger, 1994; Washburn et al., 2002). Much research focus has been on development of programs that facilitate insemination of cows at a predictable, optimized time relative to ovulation, without estrus detection (Pursley et al., 1995; Souza et al., 2008). Interestingly, despite the efficacy of TAI programs, a large number of herds in North America employ visual estrus detection or estrus detection aids as part of their reproductive management program (USDA, 2009), including the use of estrus detection in combination with TAI programs.

Modern precision technology includes automated activity-monitoring (AAM) systems, and reasonable efficiency and accuracy of estrus detection can be achieved with AAM (van Eerdenburg 2008; Hockey et al., 2010; Løvendahl and Chagunda, 2010). Few studies describe herd-level factors that affect the success of AAM systems, but individual animal factors can influence the sensitivity of AAM systems for detecting estrus. Parity, milk yield, stage of lactation, BCS, or lameness at the time of estrus can affect the probability of estrus detection with AAM systems (Arney et al., 1994; López-Gatius et al., 2005; Løvendahl and Chagunda, 2010). The first randomized trial comparing reproductive performance of an AAM-based program to TAI-based programs in North American dairy herds did not find an overall difference in time to pregnancy (Neves et al., 2012), but differences among herds were noted. Comparable overall performance was reported in a controlled trial on 2 dairy farms in Israel (Galon, 2010) and in a study that compared 3 different treatment combinations of AAM-based and TAI-based protocols for first service in lactating cows in the United States (Fricke et al., 2014). 
The first objective of our study was to describe the characteristics and motivations of producers who had implemented AAM systems. The second objective was to compare annual summary herd reproductive performance before and after the implementation of an AAM system. The final objective was to describe the reproductive performance of Canadian dairy herds managing reproduction using AAM-based programs and to compare the performance of these herds to a sample of herds without AAM systems.

\section{MATERIALS AND METHODS}

\section{Questionnaire Development and Mail Survey}

A cross-sectional study was carried out between April and July 2010 using a mail questionnaire, which was structured based on information from the survey design literature (Dohoo et al., 2009). A purposive sample of all freestall dairy herds $(\mathrm{n}=1,750)$ from the provinces of British Columbia, Alberta, Saskatchewan, Manitoba, and Ontario, Canada, enrolled in milk recording with Canwest DHI (Guelph, Ontario, Canada) in 2010 received the questionnaire. A response rate of $15 \%$ (263 returned questionnaires) was targeted to allow estimation of all proportions of responses with no more than $6 \%$ points of error (Abramson, 2011).

The questionnaire (Supplementary File 1; http:// dx.doi.org/10.3168/jds.2014-8221) was designed to collect information on herd characteristics and reproductive management practices with a focus on farms using AAM systems. The survey included 39 questions, 38 of which were closed-ended. Before implementation, the survey was reviewed by faculty and graduate students involved with dairy cattle research from the Department of Population Medicine, University of Guelph (n $=5$ ), and pretested on a convenience sample of dairy producers in Ontario $(\mathrm{n}=5)$. Questions that were unclear or otherwise problematic were revised.

In an attempt to maximize response rate, a few methods known to influence response (Dillman, 2007) were implemented: (1) the survey package included a cover letter, the survey booklet, and a prepaid addressed return envelope; (2) the cover letter clearly stated the objectives of the study, confidentiality of participation and the research team involved, and advised of a draw for 1 of 3 prizes of Can $\$ 250$ if a completed questionnaire was returned before the deadline; and (3) $3 \mathrm{wk}$ after mailing the survey, an e-mail was sent to thank producers who had already returned the questionnaire and to encourage response from those who had not yet done so. This follow-up was performed by Canwest DHI and the list of customers was not released to the re- searchers. The Research Ethics Board of the University of Guelph approved the study.

\section{Data Management and Statistical Analyses}

Following the survey administration period, a database was built using EpiData Entry 3.1 (Odense, Denmark) into which the responses from each questionnaire received were entered manually. The database entries were checked for accuracy against a sample of the returned questionnaires, which were later exported into a single file in SAS (version 9.2, SAS Institute, Cary, $\mathrm{NC}$ ). Frequency distributions were calculated for the survey variables. The associations between responses (i.e., herd characteristics, management practices, and respondents' beliefs) and use of AAM systems were assessed with Chi-squared statistics.

Any producer indicating the use of an AAM system for more than $1 \mathrm{yr}$ and consenting to extraction of DHI reproduction data was contacted via e-mail or telephone to obtain the approximate date of implementation of the estrus-detection system. Herd reproductive summary information was obtained from Canwest DHI; annual data were extracted from each farm's DairyComp 305 (Valley Agricultural Software, Tulare, CA) data file and exported into Microsoft Excel (Microsoft Corporation, Redmond, WA). The unique DHI herd number, annual 21-d pregnancy risk (PR), insemination and conception risks, and the numbers of inseminations and pregnancies for lactating cows for each year between 1999 and 2010 were compiled into a single database using SAS. Only herds for which the DHI herd number and province identification code on the annual herd summary data matched the same items in the survey were included in the analysis.

\section{Comparative Analysis Before and After Implementation of an AAM System}

For the retrospective analysis (i.e., 12-mo periods before and after implementation of the AAM system), the herd data were obtained for the year before employment of the AAM system. Because direct data on conception risk (CR) were missing for 1999 to 2004, CR was estimated for all years by dividing PR by 21-d insemination risk (IR). The choice of the after year to be used for the comparison was established on the following criteria: herds that started using the AAM system between January and June had their year after starting the subsequent calendar year, whereas herds that implemented the AAM system between July and December had their year after in the calendar year starting 1 yr later. The intent was to select years for comparison that were close in time to implementation 
of the activity system, to minimize confounding of the relationship of implementation with reproductive performance by other unmeasured variables. We hypothesized that a period of adjustment to new technology would take approximately 6 mo.

Two herds were excluded because of a disparity in province codes in the database for our study objective. To ensure completeness of insemination and pregnancy records for the full year, exclusion criteria were applied to the herd summary data set: herds with fewer than 30 $\mathrm{AI}$ or fewer than 10 pregnancies; herds with $\mathrm{PR}<2 \%$ (i.e., herds not entering all pregnancy outcome data); herds in which $\mathrm{CR}$ was $<10$ or $>80 \%$ (i.e., herds entering only services which resulted in pregnancy), and herds with an IR $<10 \%$ (i.e., incomplete data entry) were excluded.

Annual 21-d PR and IR, as well as CR, were compared before and after implementation of the AAM system using linear mixed models (MIXED procedure in SAS). All 3 models included the time variable (i.e., before or after implementation of the AAM system) as the main predictor of interest, and a categorical variable for the commercial AAM system used (5 different systems) was forced into the model because it was considered a possible confounder.

\section{Comparative Analysis Between AAM-Based and TAl-Based Programs or Other Programs}

Herds that started to manage reproduction based on an AAM system from October through December of 2009 were not included in the comparative analysis for the year 2010. Therefore, herd reproductive data for the year 2010 were compared among herds that had employed an AAM system for at least 16 mo and indicated that more than $50 \%$ of the AI were based on estrus detected by the system, herds without AAM that specified that more than $50 \%$ of the AI were based on a TAI program, and herds without AAM that were using TAI or other estrus or ovulation synchronization programs for less than $50 \%$ of AI (classified as "Other"; inferred to be herds that were breeding the majority of the cows based on observed estrus). The same exclusion criteria used previously to ensure completeness of DHI records were applied to this analysis. In addition, the annual number of pregnancies was divided by the annual average number of milking cows. It was estimated that herds with a quotient of less than $30 \%$ and a PR less than $5 \%$ were likely to have incomplete data and were excluded. Herds with fewer than 50 milking cows $(\mathrm{n}=13)$ were not included in this analysis.

The PR, CR, and IR were compared among the 3 reproduction-management systems using the mixed linear regression, with variables from the survey (i.e., herd demographics, profile of the owners, and information on management practices) included in the model. When appropriate, categorical variables with few observations per category were collapsed into other categories. Because $96 \%$ of the herds reported Holstein as the primary breed of cows, breed was not considered further. Subsequently, correlations between explanatory variables from the survey were assessed (CORR procedure in SAS) using the Spearman's rank correlation coefficient. No pairs of explanatory variables had a large $(>|0.7|)$ and significant correlation that would indicate a problem of collinearity. A manual, stepwise backward elimination procedure was employed, and all variables associated with the outcome at $P \leq 0.25$ were initially included in the model. If removal of a variable caused more than $30 \%$ change in the coefficients of significant variables in the model, the covariate was kept in the final model due to its confounding effect. Two-way interactions among management system and the significant variables from the survey were tested in the final model. No interactions were significant at $P$ $<0.05$. In all models, herd was treated as a random effect. Distributions of model residuals were assessed for homoscedasticity and normality. Least squares means were obtained for significant variables.

\section{RESULTS AND DISCUSSION}

In total, 505 questionnaires were returned, yielding a response rate of $29 \%$. Not all questions were fully answered by all respondents. Thus, some descriptive statistics were calculated with smaller sample sizes, as noted hereafter. Tables 1, 2, and 3 summarize the distribution of respondents by province, management practices, and herd characteristics relative to the use of an AAM system or not. In line with the objectives, most survey respondents represented herds that had AAM systems. As expected, our sample was largely concentrated in Ontario, because it is the province with the greatest number of dairy cows and farms in the country (CDIC, 2013) and the majority of herds in the sampling frame. Response rates by province were representative of the distribution of freestall herds in each region.

\section{Reasons for Not Adopting an AAM System}

Of the 505 surveys returned, 282 respondents (56\%) did not use pedometers or activity-monitoring systems for estrus detection. This subset of producers was asked to indicate the factors that influenced their decision to not use an AAM system (Figure 1). The majority of respondents without AAM $(53 \% ; 148 / 279)$ reported satisfaction with their current herd reproductive perfor- 
Table 1. Distribution of survey respondents by province and use of automated activity-monitoring (AAM) systems

\begin{tabular}{lrc}
\hline Province & $\begin{array}{c}\text { Not using AAM } \\
\text { systems }^{1}(\%)\end{array}$ & $\begin{array}{c}\text { Using AAM } \\
\text { systems }^{2}(\%)\end{array}$ \\
\hline Alberta & 24 & 23 \\
British Columbia & 17 & 14 \\
Manitoba & 5 & 6 \\
Ontario & 50 & 54 \\
Saskatchewan & 4 & 3 \\
\hline
\end{tabular}

${ }^{1} \mathrm{n}=282$.

${ }^{2} \mathrm{n}=220$

mance as one of the most important factors influencing their decision. Approximately 39 and $22 \%$ of the respondents reported a lack of perceived economic value (i.e., cost too high relative to benefit) and no expected improvement in herd reproductive performance if such systems were to be used as other influential factors, respectively. About 93 and $81 \%$ of these respondents did not indicate aversion to technology or unfamiliarity with available commercial systems as important in their decision not to use an AAM system. Furthermore, $30 \%$ of the respondents not using an AAM system were considering the adoption of such a tool.

\section{Reasons for Adopting an AAM System}

Almost $44 \%$ of respondents (223/505) used an AAM system for estrus detection in their herds. We emphasize that this is not an accurate estimate of the prevalence of AAM in freestall herds in Canada. The questionnaire cover letter indicated special interest in herds with AAM systems, which likely contributed (deliberately) to over-representation of these herds among respondents. These producers were asked to indicate the factors influencing their decision to employ AAM. The

Table 2. Demographic comparison and respondents' management practices in herds using and not using automated activity-monitoring (AAM) systems for estrus detection ${ }^{1}$

\begin{tabular}{|c|c|c|c|}
\hline Variable & $\begin{array}{l}\text { Not using AAM } \\
\text { systems (\%) }\end{array}$ & $\begin{array}{l}\text { Using AAM } \\
\text { systems (\%) }\end{array}$ & $P$-value \\
\hline Farmer's age & $(281)$ & $(218)$ & 0.13 \\
\hline$<30 \mathrm{yr}$ & 9 & 15 & \\
\hline 30 to $39 \mathrm{yr}$ & 19 & 18 & \\
\hline 40 to $49 \mathrm{yr}$ & 40 & 33 & \\
\hline 50 to $59 \mathrm{yr}$ & 27 & 31 & \\
\hline$\geq 60 \mathrm{yr}$ & 5 & 3 & \\
\hline Highest level of education & $(270)$ & $(210)$ & 0.92 \\
\hline High school & 36 & 36 & \\
\hline College & 44 & 42 & \\
\hline Undergraduate university & 16 & 18 & \\
\hline Postgraduate university & 4 & 4 & \\
\hline Farmer's expected time in business ${ }^{2}$ & $(280)$ & $(217)$ & 0.02 \\
\hline$\leq 20$ yr & 31 & 23 & \\
\hline$>20 \mathrm{yr}$ & 69 & 77 & \\
\hline Attendance at meetings and conferences & $(265)$ & $(209)$ & 0.43 \\
\hline Never & 6 & 3 & \\
\hline Monthly & 14 & 17 & \\
\hline Quarterly & 33 & 34 & \\
\hline Twice per year & 30.5 & 32 & \\
\hline Annually & 16.5 & 14 & \\
\hline \multicolumn{4}{|l|}{ Use of continuing education resources } \\
\hline Farm magazines & $(281)$ & $(219)$ & $0.03^{3}$ \\
\hline Yes & 94 & 98 & \\
\hline No & 6 & 2 & \\
\hline Flyers and newsletters from companies & $(269)$ & $(80)$ & 0.15 \\
\hline Yes & 82 & 75 & \\
\hline No & 18 & 25 & \\
\hline Internet & $(269)$ & $(80)$ & 0.13 \\
\hline Yes & 65 & 74 & \\
\hline No & 35 & 26 & \\
\hline Industry meetings and conferences ${ }^{4}$ & $(269)$ & $(80)$ & 0.48 \\
\hline Yes & 80 & 84 & \\
\hline No & 20 & 16 & \\
\hline
\end{tabular}

${ }^{1}$ Total population listed in parentheses.

${ }^{2}$ Duration of time that the farm is expected to be in milk production, owned by the respondent or the next generation of their family.

${ }^{3}$ Fisher's exact test.

${ }^{4}$ The 24 respondents who indicated "Other (please specify)" were not included in the analysis because categorization was not possible. 
Table 3. Herd characteristics and respondents' perception in herds using and not using automated activitymonitoring (AAM) systems for estrus detection ${ }^{1}$

\begin{tabular}{lccc}
\hline Variable & $\begin{array}{c}\text { Not using AAM } \\
\text { systems }(\%)\end{array}$ & $\begin{array}{c}\text { Using AAM } \\
\text { systems }(\%)\end{array}$ & $P$-value \\
\hline Herd size (milking cows) & $(282)$ & $(220)$ & $<0.0001$ \\
$<99$ & 62 & 37 & \\
100 to 199 & 32.5 & 43 & \\
$\geq 200$ & 5.5 & 20 & \\
Freestall flooring & $(282)$ & 59 & \\
Concrete & 73 & 16.5 & \\
Rubber & 8 & 13 & \\
Slatted & 13 & 11.5 & \\
Other & 6 & $(219)$ & \\
People involved in reproduction & $(278)$ & 27 & \\
1 & 31 & 26 & \\
2 & 50 & $(220)$ & \\
3 or more & 19 & 54 & \\
AI personnel & $(275)$ & 21 & \\
Owner or herdsman & 61.5 & 21 & \\
Employee & 14 & 4 & \\
AI company/breeder & 19 & $(191)$ & \\
Bull & 5.5 & 61 & \\
Problem finding good employees & $(219)$ & 39 & \\
Small or not a problem & 61 & $(191)$ & \\
Moderate or serious problem & 39 & 82 & \\
Problem training employees & $(213)$ & 18 & \\
Small or not a problem & 82 & $(191)$ & \\
Moderate or serious problem & 18 & 80 & \\
Problem keeping good employees & $(211)$ & 20 & \\
Small or not a problem & 81 & & \\
Moderate or serious problem & 19 & & \\
\hline
\end{tabular}

${ }^{1}$ Total population listed in parentheses.

most frequently reported reason was the desire to improve herd reproductive performance $(81 \% ; 180 / 220)$. Figure 2 illustrates the proportion of respondents that indicated specific factors as being influential in their decision. We hypothesized that welfare concerns (i.e., frequent injections required in TAI programs) was likely a driver of adoption of AAM, but that was only the sixth most reported factor.

Adoption of precision dairy technologies was suggested to depend on availability of dairy farm labor (Rodenburg, 2007), but the desire to reduce the need for labor was not ranked as a substantial motive when implementing AAM systems. Labor availability may be a driver when more costly equipment is to be adopted, such as robotic milking systems (Bergman and Rabinowicz, 2013). Moreover, the questionnaire revealed that problems related to finding, keeping, and training employees were not associated with a herd having an AAM system.

Respondents were asked to indicate the level of importance they placed on 8 specific factors in guiding their decision to implement an AAM system (Figure $3)$. Approximately $42 \%(86 / 203)$ indicated consultation with other farmers, $35 \%(71 / 201)$ cited consultation with partners and family members, and $27 \%$ (53/197) noted formal investment analysis as very important factors. Information from dairy farm magazines $(50 \%$;
101/201), advice from veterinarians and dairy consultants $(47 \% ; 97 / 206)$, and informal calculations to examine financial impact $(41 \% ; 82 / 199)$ were rated as important factors when deciding about the employment of an activity system. Consultation with other farmers was ranked as the most important factor influencing their decision. The same behavior was recently reported by Swedish farmers; respondents to a survey on robotic milking systems placed advice and prior experience from other farmers with robotic milking systems as the most prominent factor when deciding on investing in a new technology (Bergman and Rabinowicz, 2013).

\section{Reproductive Management Practices Based on AAM Systems}

Survey participants who were using an AAM system for cows or heifers were asked to describe the use of the system in each group of animals. Approximately $96 \%$ (215/223) of respondents with AAM used the system for cows and $27 \%(60 / 223)$ used it for heifers. Table 4 summarizes the proportion of AAM systems by commercial supplier, respondents' satisfaction with their system, and specific variables related to the system's use. One system (Heatime; SCR Engineers Ltd., Netanya, Israel) was more commonly used by respondents than other systems. We caution that the proportions of 


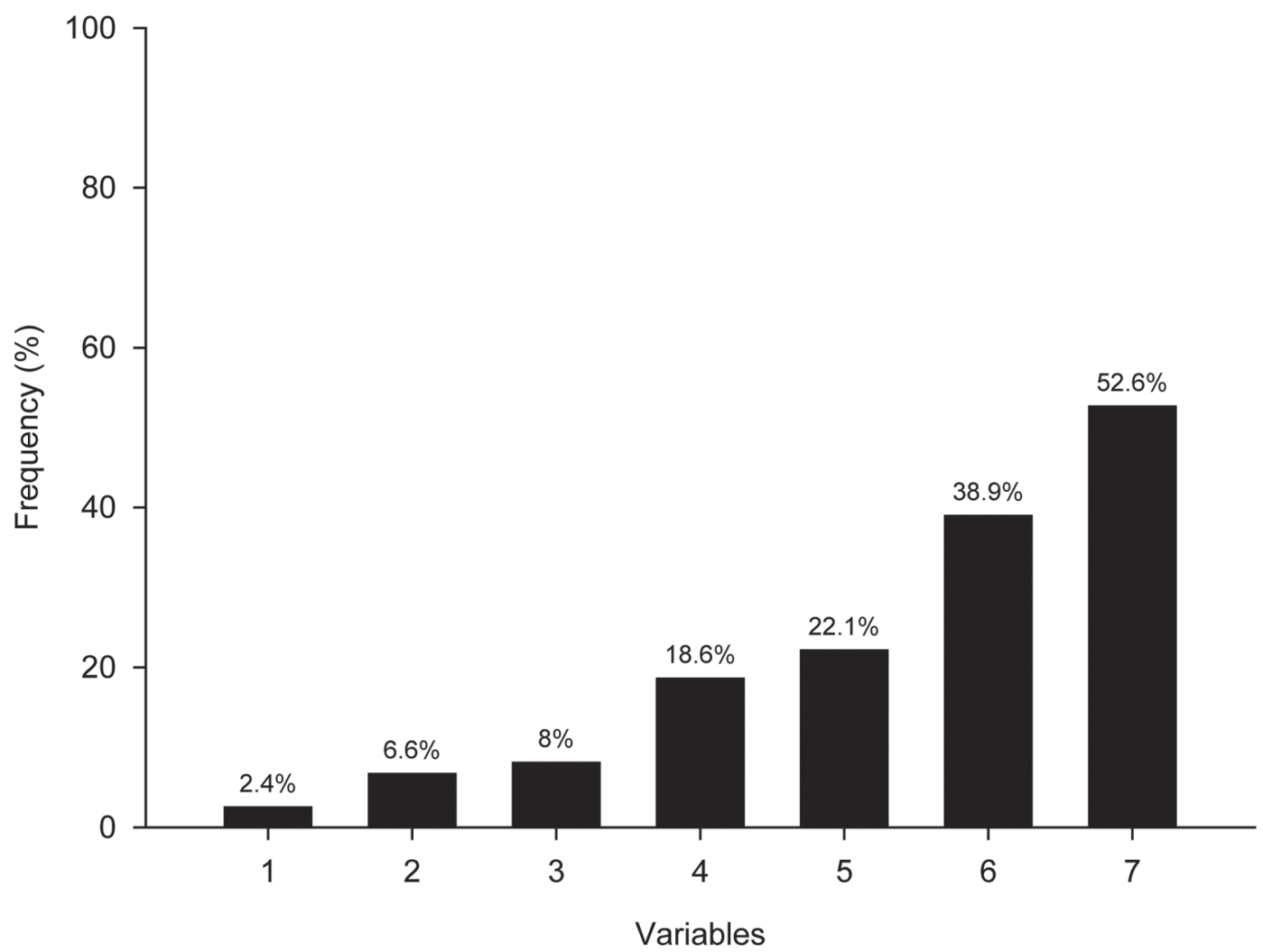

Figure 1. Frequency distribution of reasons for not adopting an automated activity-monitoring system among 279 respondents sent a mail questionnaire. Variables assessed: $1=$ too difficult to use; $2=$ dislike technology; $3=$ poor integration with other farm software; $4=$ not familiar with the systems available; $5=$ do not think herd reproductive performance would improve; $6=$ lack of perceived economic value; $7=$ satisfied with herd reproductive performance. The category "Other (please specify)" was omitted because of the inability to correctly categorize those responses.

AAM systems by commercial supplier obtained in our questionnaire may not accurately describe the distribution of the different systems employed in Canada. Some AAM systems are integrated with other milking equipment and software, including daily milk yield meters, and herds with this equipment may be less likely to be enrolled in DHI. Such farms would not have received the questionnaire, given that the herds surveyed had to be enrolled in DHI.

In our sample (Table 4), 93\% (53/57) of respondents using an AAM system for heifers indicated that more than $50 \%$ of these AI were based on estrus detected by the system. In contrast, only 58\% (121/210) of respondents using an AAM system for lactating cows indicated that more than $50 \%$ of inseminations were based on estrus detected by the automated system. Valenza et al. (2012) measured estrus activity in 89 lactating dairy cows after an estrus-synchronization protocol and found that $29 \%$ of the animals were not detected in estrus by the AAM system. This may be partially explained by reduced estrus activity associated with greater milk yield and confined housing with only concrete floors (López-Gatius et al., 2005; Palmer et al., 2010; Ranas- inghe et al., 2010). In addition, the number of missed estrus events and false alerts may vary based on the system used and the activity thresholds employed (Firk et al., 2002; Holman et al., 2011). Therefore, it is not surprising that up to $30 \%$ of inseminations might not be based on the AAM system, but the reasons for this were not probed in the questionnaire. Respondents specified the proportion of animals that would not be bred after the voluntary waiting period if estrus was signaled by the system. Approximately $71 \%(146 / 207)$ indicated that less than $10 \%$ of the cows would not be bred after an estrus alarm, whereas $22 \%(46 / 207)$ reported this proportion to be between 10 and $25 \%$. Similarly, $84 \%(46 / 55)$ of producers indicated that less than $10 \%$ of heifers would not be bred after the system indicated estrus, and 15\% (8/55) reported that this occurred 10 to $25 \%$ of the time. The survey asked why an animal would not be inseminated despite an estrus signal from the AAM system, with the following choices: (1) on observation the cow (or heifer) does not appear to be in estrus; (2) the cow (or heifer) has already been inseminated but does not have a confirmed pregnancy; (3) the cow (or heifer) has already been di- 


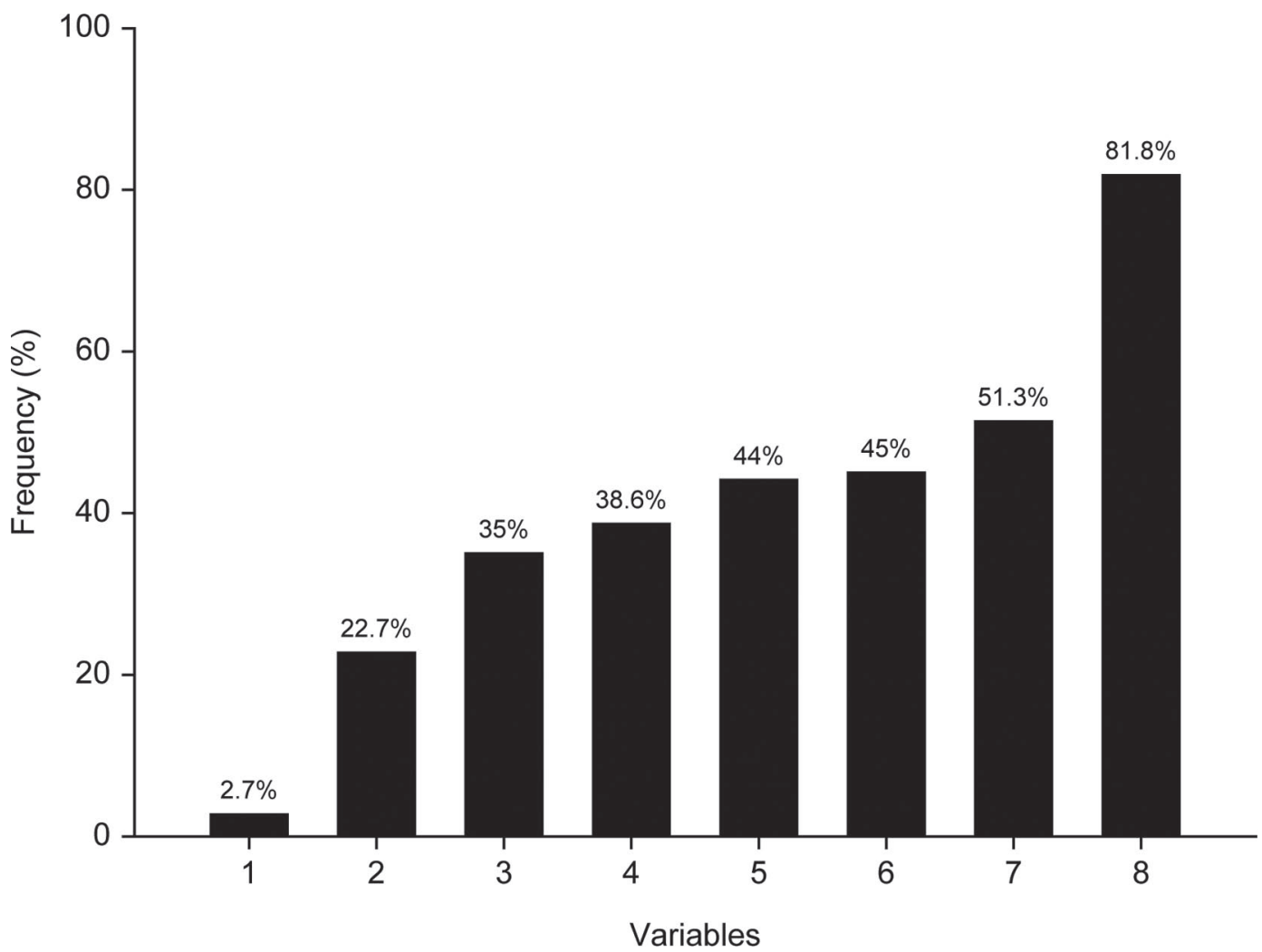

Figure 2. Frequency distribution among 220 respondents sent a questionnaire of reasons for adopting an automated activity-monitoring system. Variables assessed: $1=$ going organic; $2=$ inability of workers to detect estrus; $3=$ concern about frequent injections required in timed AI programs; 4 = desire to reduce labor; $5=$ desire to breed cows based on estrus detection; $6=$ chance to monitor health along with estrus; $7=$ lack of time to detect estrus themselves; $8=$ desire to improve herd reproductive performance. The category "Other (please specify)" has been omitted because of the inability to correctly categorize those responses.

agnosed pregnant; (4) the cow (or heifer) is unhealthy; (5) I have chosen to not rebreed the cow (or heifer); (6) the cow's milk production is high enough that I wish to delay breeding; (7) the heifer is too small; and (8) other-please describe. The 3 most commonly cited reasons for cows were items 5, 4, and 3. Each of these reasons was in the top 3 choices in more than $22 \%$ of responses. For heifers, there was insufficient variability of the responses for complete analysis; however, the most frequent reason given not to inseminate was because the heifer was too small $(55 / 141 ; 44 \%)$.

Approximately $72 \%$ of the respondents with AAM were performing AI at least twice daily and the most common interval from an estrus alarm to AI was 7 to $12 \mathrm{~h}$ (Table 4). Respondents reported that $86 \%$ of AI were performed by $12 \mathrm{~h}$ after the estrus alarm. This indicates that most respondents were using their AAM system based on the reported optimum interval for AI conception risk of 9 to $16 \mathrm{~h}$ after the threshold of activity is passed (i.e., onset of estrus alarm; Stevenson et al., 2014) or by $16 \mathrm{~h}$ after the peak of estrus activity (Maatje et al., 1997; Bar, 2010).

\section{Reproductive Performance Before and After the Adoption of an AAM System}

Respondents were asked to recall the month and year of adoption of the AAM system. Retrospective components in cross-sectional studies are prone to recall bias (Dillman, 2007; Dohoo et al., 2009). The consequences of a wrongly reported date would be a loss of statistical power to detect differences in the reproductive outcomes analyzed for the year before versus after adoption of the system. We hypothesized that recall bias was less likely to occur in this case, considering that investment in an AAM system is costly and farmers would be likely to remember when such an event happened. Allowing an adaptation period of 6 mo after the reported AAM implementation date when selecting the after period for comparison should minimize bias of herd performance due to unfamiliarity with the system. Other than the main reproductive management program used, nutritional, managerial, disease, environmental, and genetic factors influence reproductive performance in a dairy herd (Lucy, 2001; Schefers et al., 2010). Considering 


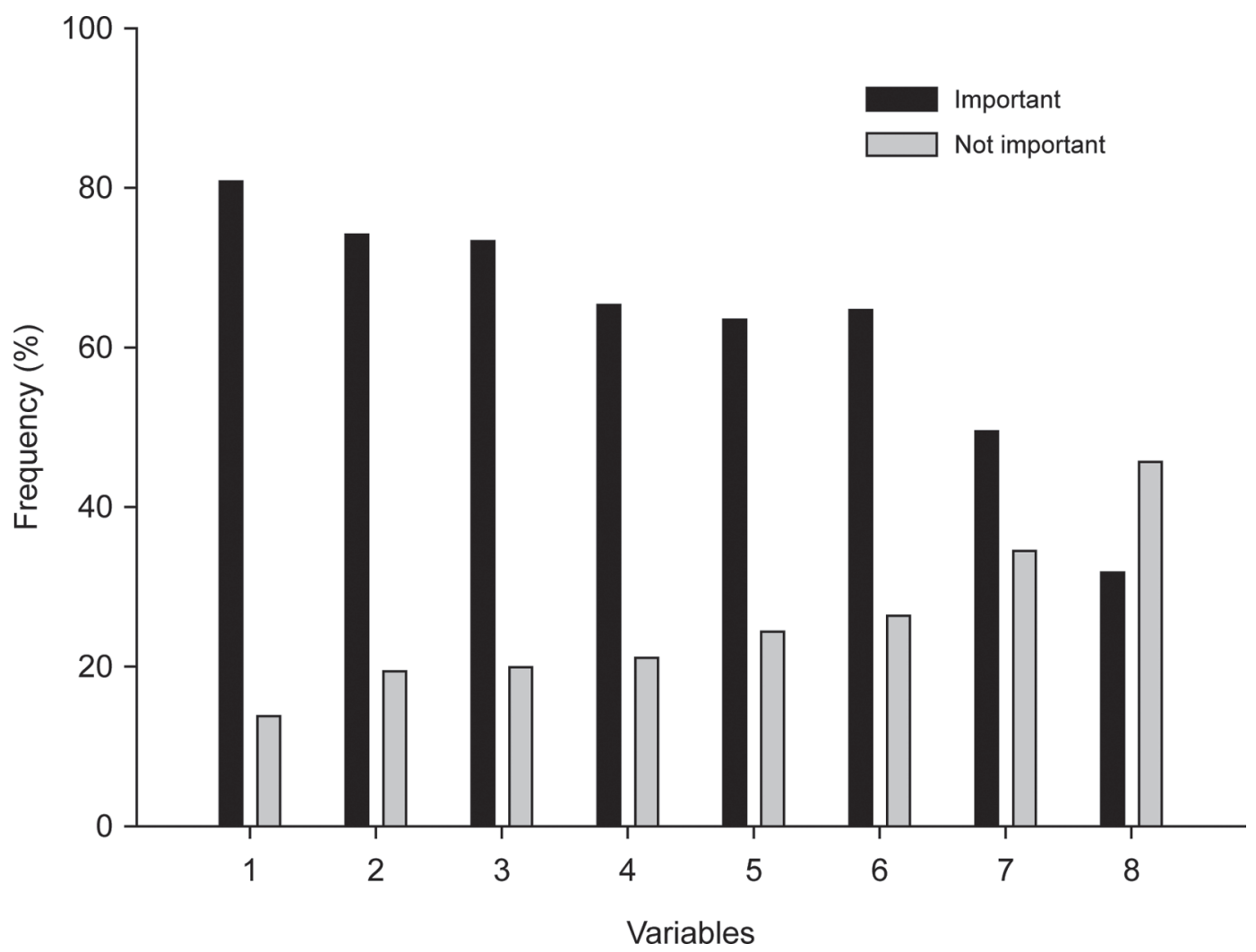

Figure 3. Frequency distribution of 220 responses (3 responses were missing) to a questionnaire on which factors were "very important" or "important" (collapsed into a single category: "important") or "not important" in deciding to implement an automated activity-monitoring system for estrus detection. Variables assessed: $1=$ consultation with other farmers; $2=$ consultation with family members and business partners; 3 $=$ advice from veterinarians or dairy consultants; $4=$ informal calculations to examine financial impact; $5=$ investment analyses; $6=$ magazines; $7=$ conferences and meetings; $8=$ Internet resources. The remaining percentage to total $100 \%$ for each variable corresponds to the fraction of instances in which the "not applicable" choice was selected. These were $5,6,7,14,12,9,16$, and $23 \%$ for variables 1 through 8 , respectively.

that the objective of our study was to describe population-average (rather than herd-specific) reproductive performance for 12 -mo periods before and after implementation of the system, in which herds were compared with themselves, the methods applied suit the purpose.

Following all exclusion criteria as previously detailed, 44 herds remained for the analysis. Approximately $11 \%$ of the herds employed AfiAct (Afimilk, Kibbutz Afikim, Israel), 14\% CowTrakker (Bou-Matic, Madison, WI), 16\% Alpro (DeLaval, Tumba, Sweden), 25\% DairyPlan C21 (GEA Farm Technologies, Bonen, Germany), and $34 \%$ Heatime (SCR Engineers Ltd.). It was assumed that from the time a herd implemented the system to the time of the survey administration, no change occurred in the commercial system used within a herd.

Table 5 displays the least squares means of the measures of herd reproductive performance. Overall, for the 12-mo periods before and after employment of the AAM system, a mean increase of $2.1 \%$ points in $\mathrm{PR}$ $(P<0.01)$ and $7.6 \%$ points in IR $(P<0.0001)$ was observed after implementation. In contrast, the estimated annual CR showed no significant difference $(P<$
0.24) before versus after AAM implementation. In all 3 models the commercial system used was included as a covariate, but this variable was not significant.

It was hypothesized that a greater $\mathrm{PR}$ would be caused by an increase in IR after implementation of an AAM system. Pregnancy rate can be improved by enhancing AI submission or CR, the latter being more challenging to achieve (Ferguson and Galligan, 2000; Fricke et al., 2005; LeBlanc, 2005).

\section{Reproductive Performance of AAM-Based Programs Versus TAI-Based Programs or Other Programs}

In total, 166 herds contributed to this analysis (Table 6). Approximately $21 \%$ of the herds were managing reproduction with an AAM system, whereas 32\% (53/166) were using a routinely scheduled estrus-synchronization or TAI program for more than $50 \%$ of the AI for lactating cows. Of the 53 herds using TAI, about $53 \%$ were using OvSynch or one of its variants and $34 \%$ used $\mathrm{PGF}_{2 \alpha}$ followed by estrus detection for inseminations. Of the 35 herds using an AAM system included in the 
Table 4. Proportion of automated activity-monitoring (AAM) systems by commercial supplier, respondents' satisfaction, and respondentreported variables related to the system's use ${ }^{1}$

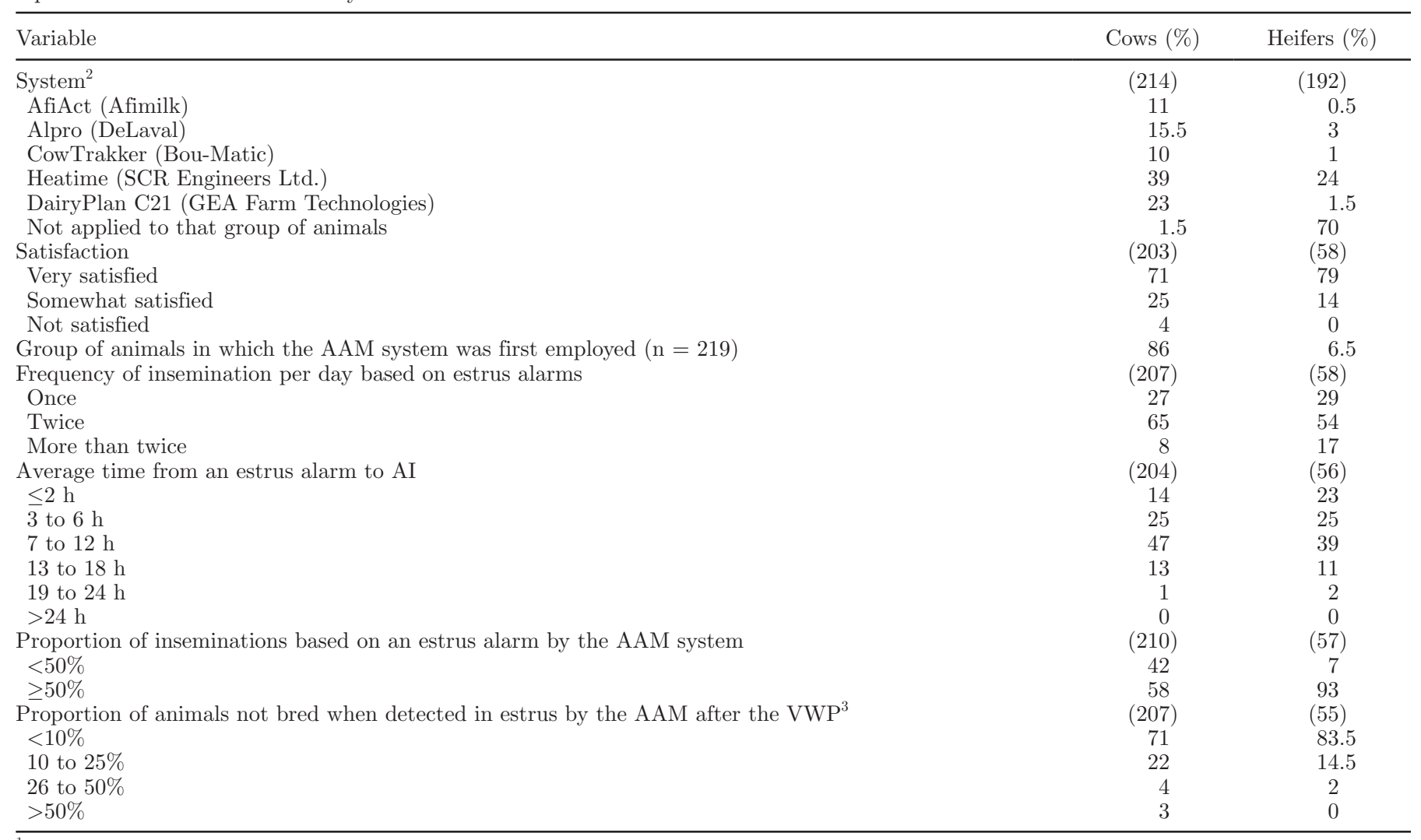

${ }^{1}$ Total population listed in parentheses.

${ }^{2}$ Afimilk, Kibbutz Afikim, Israel; DeLaval, Tumba, Sweden; Bou-Matic, Madison, WI; SCR Engineers Ltd., Netanya, Israel; GEA, Bonen, Germany.

${ }^{3}$ Voluntary waiting period.

analysis, 2 herds used Alpro (DeLaval), 4 herds used AfiAct (Afimilk), 5 CowTrakker (Bou-Matic), 9 DairyPlan C21 (GEA Farm Technologies), and 14 Heatime (SCR Engineers Ltd.); 1 response was missing. The majority of these herds (24 out of 33 ) were inseminating the cows twice daily, 7 of 33 only inseminated once daily, and in 2 herds AI occurred more than twice daily; 2 responses were missing.

The remaining $47 \%(78 / 166)$ of the herds included in the analysis were neither using an AAM system nor breeding the majority of the cows based on systematic estrus synchronization or TAI programs. The questionnaire was not designed to describe specific reproductive management procedures for this third group, but it can be inferred that in herds without AAM in which less than $50 \%$ of AI were based on estrus synchronization or a TAI program, AI was based on observed signs of estrus (i.e., visual estrus detection or use of estrus-detection aids other than AAM systems). The median herd size for herds with activity systems was 149 lactating cows, whereas herds using estrus synchronization or a TAI and other programs each had a median of 99 lactating cows. Least squares means for the 3 reproductive metrics analyzed are in Table 6 . Pregnancy risk was $1.9 \%$ points greater in herds with AAM than in the "other" group, but not different between herds with AAM and

Table 5. Differences in annual herd reproductive performance between the year before and the year after implementation of an automated activity-monitoring (AAM) system for estrus detection in 44 freestall herds

\begin{tabular}{lccc}
\hline & \multicolumn{2}{c}{ Mean $(95 \% \mathrm{CI})$} & \\
\cline { 2 - 3 } Metric & Year before & Year after & P-value \\
\hline Pregnancy risk & $14.9(13.7-16.1)$ & $17.0(15.8-18.2)$ & 0.01 \\
Estimated conception risk & $37.2(34.1-40.2)$ & $34.9(31.9-37.9)$ & 0.24 \\
Insemination risk & $42.0(38.9-45.1)$ & $49.6(46.5-52.7)$ & $<0.0001$ \\
\hline
\end{tabular}


Table 6. Annual reproductive performance in herds using an automated activity-monitoring (AAM) system for estrus detection, a timed artificial insemination (TAI)-based program, or other breeding programs for $\geq 50 \%$ of inseminations in 2010 ( $\mathrm{n}=166$ herds)

\begin{tabular}{lcccc}
\hline Metrics & $\begin{array}{l}\text { Mean }(95 \% \mathrm{CI}) \\
\text { AAM }(\mathrm{n}=35)\end{array}$ & $\begin{array}{c}\text { Mean }(95 \% \mathrm{CI}) \\
\text { TAI }(\mathrm{n}=53)\end{array}$ & $\begin{array}{c}\text { Mean }(95 \% \mathrm{CI}) \\
\text { other }^{1}(\mathrm{n}=78)\end{array}$ & $\begin{array}{c}\text { Overall } \\
P \text {-value }\end{array}$ \\
\hline $\mathrm{PR}^{2}$ & $18.0^{\mathrm{a}}(16.7-19.4)$ & $17.3^{\mathrm{ab}}(16.1-18.5)$ & $16.1^{\mathrm{b}}(15.2-17.0)$ & 0.05 \\
$\mathrm{CR}^{3}$ & $39.4(36.3-42.4)$ & $38.1(35.4-41.0)$ & $40.5(38.3-42.7)$ & 0.29 \\
$\mathrm{IR}^{4}$ & $49.7^{\mathrm{a}}(46.0-53.4)$ & $49.0^{\mathrm{a}}(45.6-52.4)$ & $43.0^{\mathrm{b}}(40.2-45.7)$ & $<0.001$ \\
\hline${ }^{\mathrm{a}, \mathrm{b}} \mathrm{Groups}$ in a row without a common superscript letter differ $(P<0.05)$. \\
${ }^{1} \mathrm{Other}=$ herds that were breeding the majority of the cows based on observed estrus. \\
${ }^{2} \mathrm{PR}=$ pregnancy risk; accounting for expected future time in business and hoof trimming of midlactation cows. \\
${ }^{3} \mathrm{CR}=$ conception risk; accounting for expected future time in business, producer's level of education, herd size, \\
frequency of hoof trimming per year, and hoof trimming of fresh cows. \\
${ }^{4} \mathrm{IR}=$ insemination risk; accounting for herd size and hoof trimming of fresh cows.
\end{tabular}

herds using TAI-based programs $(P=0.41)$. Similar reproductive results have been obtained in randomized trials when AAM- and TAI-based programs were compared (Galon, 2010; Neves et al., 2012).

We emphasize that reproductive performance is influenced by many factors, but the reproductive management program is one important factor influencing the present outcomes. A few studies have explored the associations of herd characteristics, housing, management practices, and farmers' psychosocial profile with herd reproductive performance (Caraviello et al., 2006; Bach et al., 2008; Schefers et al., 2010). In the present study, we collected information on the farmers' demographics and perceptions, herd characteristics, and some reproductive management practices. Those variables were investigated for possible associations with herd reproductive performance. Respondents who indicated that they expected their farm to be in business for less than 20 yr (e.g., to a subsequent generation) had a lower PR $(15.6 \%)$ than producers who expected to be in the farming business for more than $20 \mathrm{yr}$ (17.8\%), $P=0.002$.

Conception risk was not different between herds with and without AAM systems, but 5 other variables remained in the final model (Table 6). Both the education level of the owner and the frequency of maintenance foot trimming in the herd were significant covariates $(P=0.03$ in both cases). The mean $\mathrm{CR}$ was greater in those herds where the owner's highest level of education was high school (41\%), compared with owners with a college education $(37 \% ; P=0.009)$, but not different to those with undergraduate or postgraduate university education $(39 \% ; P=0.33)$. The magnitude of these differences is small and we speculate that the association of CR with level of education is confounded by variables that we did not measure (e.g., sire selection or details of AI technique). The mean CR was greater in herds that underwent regular foot trimming once a year $(42 \%)$ compared with herds that underwent foot trimming twice $(37 \% ; P=0.01)$ or 3 times or more in a year $(38 \% ; P=0.05)$. Perhaps herds trimming more frequently had a greater prevalence of lameness, which has been shown to impair reproduction (Sprecher et al., 1997; Garbarino et al., 2004). This does not imply that more frequent hoof trimming reduces herd CR.

Overall, IR was different between herds with AAM systems or those using TAI programs compared with farms managing reproduction based on other programs $(P=0.03$ and $P=0.02$, respectively; Table 6$)$. Accurate estrus detection is difficult for some herds (Heersche and Nebel, 1994). Not surprisingly, IR was lower in herds with other programs (43\%) compared with herds using AAM- (50\%) and TAI-based (49\%) programs. Our finding is in agreement with other studies demonstrating a high AI submission rate when using TAI programs (Pursley et al., 1995) or an AAM-based program (Neves et al., 2012; Fricke et al., 2014).

\section{CONCLUSIONS}

Overall, reproductive performance was not different between herds managing reproduction with AAM- or TAI-based programs. On average, herds that adopted an AAM system had an increase in PR and IR, whereas the CR was unchanged when compared with the reproductive performance from the previous year. This was the first study to investigate the decision-making process of dairy producers when adopting AAM systems. The major drivers for adoption of an AAM system were the desire for improvement in herd reproductive performance and opinions and experiences from other farmers. Our results facilitate understanding of sociopsychological characteristics that are involved with producers' preferences in adopting a variety of herd management practices. These results support the findings from randomized trials that AAM-based programs can yield comparable reproductive performance to TAIbased programs. 


\section{ACKNOWLEDGMENTS}

This project was funded by the Ontario Ministry of Agriculture and Rural Affairs (Guelph, ON, Canada). We thank Canwest DHI (Guelph, ON, Canada) for their support and appreciate the participation of all farmers in the survey. We are also grateful to Lindsay Oxby (Ontario Veterinary College, Guelph, Canada) for entering the questionnaire data.

\section{REFERENCES}

Abramson, J. H. 2011. WINPEPI updated: Computer programs for epidemiologists, and their teaching potential. Epidemiol. Perspect. Innov. 8:1.

Arney, D. R., S. E. Kitwood, and C. J. C. Phillips. 1994. The increase in activity during oestrus in dairy cows. Appl. Anim. Behav. Sci. 40:211-218.

Bach, A., N. Valls, A. Solans, and T. Torrent. 2008. Associations between nondietary factors and dairy herd performance. J. Dairy Sci. 91:3259-3267.

Bar, D. 2010. Optimal timing of insemination using activity collars. Page 100 in The First North American Conference on Precision Dairy Management, Toronto, Canada. Progressive Dairy Operators, Elora, ON, Canada.

Bergman, K., and E. Rabinowicz. 2013. Adoption of the automatic milking system by Swedish milk producers. AgriFoods Economics Centre. Accessed Jan. 22, 2014. http://www.agrifood.se/Files/ AgriFood_WP20137.pdf.

Caraviello, D. Z., K. A. Weigel, P. M. Fricke, M. C. Wiltbank, M. J. Florent, N. B. Cook, K. V. Nordlund, N. R. Zwald, and C. L. Rawson. 2006. Survey of management practices on reproductive performance of dairy cattle on large US commercial farms. J. Dairy Sci. 89:4723-4735.

CDIC. 2013. Dairy facts and figures: Number of farms, dairy cows and dairy heifers. Accessed Jan. 20, 2014. http://www.dairyinfo.gc.ca/ index_e.php?s1=dff-fcil\&s2=farm-ferme\&s $3=\mathrm{nb}$.

Dillman, D. A. 2007. Mail and Internet Surveys: The Tailored Design Method. 2nd ed. John Wiley \& Sons, Inc, Hoboken, NJ.

Dohoo, I., W. Martin, and H. Stryhn. 2009. Veterinary Epidemiologic Research. 2nd ed. AVC Inc., Charlottetown, PEI, Canada.

Ferguson, J. D., and D. T. Galligan. 2000. Assessment of reproductive efficiency in dairy herds. Compend. Contin. Educ. Pract. Vet. 22:150-159.

Firk, R., E. Stamer, W. Junge, and J. Krieter. 2002. Automation of oestrus detection in dairy cows: A review. Livest. Prod. Sci. 75:219-232.

Fricke, P., S. Stewart, P. Rapnicki, S. Eicker, and M. Overton. 2005. Pregnant vs. open: Getting cows pregnant and the money it makes. Page 49-62 in Proceedings of the 7th Western Dairy Management Conference, Reno, NV. Dairy Conferences LLC, Manhattan, KS.

Fricke, P. M., J. O. Giordano, A. Valenza, G. Lopes Jr., M. C. Amundson, and P. D. Carvalho. 2014. Reproductive performance of lactating dairy cows managed for first service using timed artificial insemination with or without detection of estrus using an activitymonitoring system. J. Dairy Sci. 97:2771-2781.

Galon, N. 2010. The use of pedometry for estrus detection in dairy cows in Israel. J. Reprod. Dev. 56(Suppl):S48-S52.

Galvão, K. N., P. Federico, A. De Vries, and G. M. Schuenemann. 2013. Economic comparison of reproductive programs for dairy herds using estrus detection, timed artificial insemination, or a combination. J. Dairy Sci. 96:2681-2693.

Garbarino, E. J., J. A. Hernandez, J. K. Shearer, C. A. Risco, and W. W. Thatcher. 2004. Effect of lameness on ovarian activity in postpartum Holstein cows. J. Dairy Sci. 87:4123-4131.
Heersche, G., Jr., and R. L. Nebel. 1994. Measuring efficiency and accuracy of detection of estrus. J. Dairy Sci. 77:2754-2761.

Hockey, C., J. Morton, S. Norman, and M. McGowan. 2010. Evaluation of a neck mounted 2-hourly activity meter system for detecting cows about to ovulate in two paddock-based Australian dairy herds. Reprod. Domest. Anim. 45:e107-e117.

Holman, A., J. Thompson, J. E. Routly, J. Cameron, D. N. Jones, D. Grove-White, R. F. Smith, and H. Dobson. 2011. Comparison of oestrus detection methods in dairy cattle. Vet. Rec. 169:47-52.

LeBlanc, S. 2005. Overall reproductive performance of Canadian dairy cows: Challenges we are facing. Adv. Dairy Technol. 17:137-157.

López-Gatius, F., P. Santolaria, I. Mundet, and J. L. Yániz. 2005. Walking activity at estrus and subsequent fertility in dairy cows. Theriogenology 63:1419-1429.

Løvendahl, P., and M. G. G. Chagunda. 2010. On the use of physical activity monitoring for estrus detection in dairy cows. J. Dairy Sci. 93:249-259.

Lucy, M. C. 2001. Reproductive loss in high-producing dairy cattle: Where will it end? J. Dairy Sci. 84:1277-1293.

Maatje, K. S. H. Loeffler, and B. Engel. 1997. Predicting optimal time of insemination in cows that show visual signs of estrus by estimating onset of estrus with pedometers. J. Dairy Sci. 80:1098-1105.

Neves, R. C., K. E. Leslie, J. S. Walton, and S. J. LeBlanc. 2012 Reproductive performance with an automated activity monitoring system versus a synchronized breeding program. J. Dairy Sci. 95:5683-5693.

Palmer, M. A., G. Olmos, L. A. Boyle, and J. F. Mee. 2010. Estrus detection and estrus characteristics in housed and pastured Holstein-Friesian cows. Theriogenology 74:255-264.

Pursley, J. R., M. O. Mee, and M. C. Wiltbank. 1995. Synchronization of ovulation in dairy cows using $\mathrm{PGF}_{2 \alpha}$ and $\mathrm{GnRH}$. Theriogenology 44:915-923.

Ranasinghe, R. M. S. B. K., T. Nakao, K. Yamada, and K. Koike. 2010. Silent ovulation, based on walking activity and milk progesterone concentrations, in Holstein cows housed in a free-stall barn. Theriogenology 73:942-949.

Rodenburg, J. 2007. Precision dairy management and the future of dairy production in Ontario. Accessed Jan. 23, 2015. http://www. omafra.gov.on.ca/english/livestock/dairy/facts/07-065.htm.

Schefers, J. M., K. A. Weigel, C. L. Rawson, N. R. Zwald, and N. B. Cook. 2010. Management practices associated with conception rate and service rate of lactating Holstein cows in large, commercial dairy herds. J. Dairy Sci. 93:1459-1467.

Senger, P. L. 1994. The estrus detection problem: New concepts, technologies, and possibilities. J. Dairy Sci. 77:2745-2753.

Souza, A. H., H. Ayres, R. M. Ferreira, and M. C. Wiltbank. 2008. A new presynchronization system (double-Ovsynch) increases fertility at first postpartum timed AI in lactating dairy cows. Theriogenology 70:208-215.

Sprecher, D. J., D. E. Hostetler, and J. B. Kaneene. 1997. A lameness scoring system that uses posture and gait to predict dairy cattle reproductive performance. Theriogenology 47:1179-1187.

Stevenson, J. S., S. L. Hill, R. L. Nebel, and J. M. DeJarnette. 2014 Ovulation timing and conception risk after automated activity monitoring in lactating dairy cows. J. Dairy Sci. 97:4296-4308.

USDA. 2009. Dairy 2007, Part IV: Reference of Dairy Cattle Health and Management Practices in the United States. Accessed Jan. 21 2014. http://www.aphis.usda.gov/animal_health/nahms/dairy/ downloads/dairy07/Dairy07_dr_PartIV.pdf.

Valenza, A., J. O. Giordano, G. Lopes Jr., L. Vincenti, M. C. Amundson, and P. M. Fricke. 2012. Assessment of an accelerometer system for detection of estrus and treatment with gonadotropin-releasing hormone at the time of insemination in lactating dairy cows. J. Dairy Sci. 95:7115-7127.

van Eerdenburg, F. J. C. M. 2008. The pedometer, an automated aid in the detection of estrus. Vet. Q. 30(Suppl. 1):49-57.

Washburn, S. P., W. J. Silvia, C. H. Brown, B. T. McDaniel, and A. J. McAllister. 2002. Trends in reproductive performance in southeastern Holstein and Jersey DHI herds. J. Dairy Sci. 85:244-251. 